\title{
How does tuberculosis relate to HIV positive and HIV negative drug users?
}

Sytze T Keizer, Miranda M W Langendam, Henk van Deutekom, Roel A Coutinho, Erik J C van Ameijden

\begin{abstract}
Objectives-(1) To compare the incidence of active tuberculosis in HIV positive and HIV negative drug users. (2) To describe the main characteristics of the tuberculosis cases.

Design-A prospective study was performed from 1986 to 1996 as part of an ongoing cohort study of HIV infection in Amsterdam drug users.

Methods-Data from the cohort study, including HIV serostatus and CD4-cell numbers, were completed with data from the tuberculosis registration of the tuberculosis department of the Amsterdam Municipal Health Service. Analyses were carried out with person time and survival methods.
\end{abstract}

Results-Of 872 participants, 24 persons developed culture confirmed tuberculosis during a total follow up period of 4000 person years ( 0.60 per 100 py, $95 \%$ CI: 0.40 , 0.90). Nineteen cases were HIV positive (1.54 per 100 py, 95\% CI: $0.86,2.11)$ and five HIV negative $(0.18$ per 100 py, $95 \% \mathrm{CI}$ : $0.08,0.43)$. Multivariately HIV infection (relative risk: $12.9 ; 95 \% \mathrm{CI}: 3.4,48.8$ ) and age above 33 years (RR: 6.8 ; 95\% CI: 1.3 , 35.0 , as compared with age below 27) increased the risk for tuberculosis substantially. Additional findings were: (1) 13 of 22 pulmonary tuberculosis cases (59\%) were detected by half yearly radiographic screening of the chest; (2) tuberculosis occurred relatively early in the course of HIV infection at a mean CD4 cell number of $390 / \mu 1$; (3) an estimated two thirds of the incidence of tuberculosis observed among HIV positive cases was caused by reactivation; (4) all but one patient completed the tuberculosis treatment.

Conclusion-HIV infection increases the risk for active tuberculosis in Amsterdam drug users 13-fold. The incidence of tuberculosis in HIV negative drug users is still six times higher than in the overall Amsterdam population. In the absence of contact tracing and screening with tuberculin skin tests, periodic chest radiographic screening contributes substantially to early casefinding of active tuberculosis in Amsterdam drug users. (F Epidemiol Community Health 2000;54:64-68)

Epidemiological studies in the United States during the mid-eighties showed for the first time a relation between an increased incidence of tuberculosis and the HIV epidemic. ${ }^{1}$ Since that time the interaction between both agents has been disastrous, especially in Third World countries. ${ }^{23}$ In the Netherlands an increase of the tuberculosis incidence since 1987, after decennia of decrease, could not be explained by the HIV epidemic. ${ }^{4}$ In Amsterdam where half of all AIDS cases and a quarter of all smear positive tuberculosis cases in the Netherlands are diagnosed, some 6000 opioid addicts reside, a group already associated with an increased risk for tuberculosis before the HIV epidemic. ${ }^{5}$ The approximately 2500 injecting drug users in Amsterdam of whom 30\% became infected with $\mathrm{HIV}^{6-8}$ might, like in other cities, ${ }^{9}$ illustrate the connection between HIV and tuberculosis most evidently. Tuberculosis infection and active tuberculosis already proved more incident in Amsterdam drug users than in the general Dutch population ${ }^{10}{ }^{11}$ and drug users elsewhere in the Netherlands. ${ }^{12} \mathrm{~A}$ recent study using molecular epidemiological methods showed a high degree of active transmission of $M$ tuberculosis among Amsterdam drug users. ${ }^{13}$ Because we experienced problems with contact investigation and a poor compliance with isoniazid prophylaxis in this population, chest radiographic screening for pulmonary tuberculosis twice a year was started in 1988 for drug users attending methadone programmes as an alternative control strategy, yielding four cases per 1000 chest radiographs. ${ }^{14}{ }^{15}$ Screening as well as compliance to tuberculosis treatment are required for participation in the methadone programme.

We studied the influence of HIV infection on the incidence of tuberculosis as part of a comprehensive study among HIV positive and HIV negative drug users in Amsterdam. Besides contributing to general knowledge, our study also provides data of interest to evaluate our efforts to control tuberculosis in this particular population.

\section{Methods}

Amsterdam adopted the concept of harm reduction to minimise the negative consequences of drug use. Among the contributing programmes, methadone distribution has a coverage of $60 \%$ of all 6000 opioid addicts. Chest radiographic screening for tuberculosis in six monthly intervals has been performed since 1988 among some 3000 methadone clients of the Municipal Health Service.

Since December 1985, injecting drug users and non-injecting drug users without AIDS are recruited via methadone programmes, an STD clinic for prostitutes, and word of mouth to participate on a voluntary basis in an open 
Table 1 General characteristics of 872 drug users at entry in the study

\begin{tabular}{|c|c|c|c|c|}
\hline Patient characteristics & $\begin{array}{l}\text { Total } \\
(n=872)(\%)\end{array}$ & $\begin{array}{l}\text { HIV positive } \\
(n=872)(\%)\end{array}$ & $\begin{array}{l}\text { HIV negative } \\
(n=872)(\%)\end{array}$ & $\chi^{2} p$ value \\
\hline \multicolumn{4}{|l|}{ Gender } & \multirow[t]{3}{*}{$>0.05(\mathrm{NS})$} \\
\hline female & $358(41.1)$ & $91(40.4)$ & $267(41.3)$ & \\
\hline male & $514(58.9)$ & $134(59.6)$ & $380(58.7)$ & \\
\hline \multicolumn{4}{|l|}{ Age } & \multirow[t]{4}{*}{$>0.05$ (NS) } \\
\hline$\leqslant 27$ & $292(33.5)$ & $60(26.7)$ & $232(35.9)$ & \\
\hline $28-32$ & $276(31.7)$ & $83(36.9)$ & $193(29.8)$ & \\
\hline$\geqslant 33$ & $304(34.9)$ & $82(36.4)$ & $222(34.3)$ & \\
\hline \multicolumn{4}{|l|}{ Nationality } & \multirow[t]{4}{*}{0.0005} \\
\hline Dutch & $634(72.7)$ & $140(62.2)$ & $494(76.4)$ & \\
\hline German & $126(14.4)$ & $51(22.7)$ & $75(11.6)$ & \\
\hline other & $112(12.8)$ & $34(15.1)$ & $78(12.1)$ & \\
\hline \multicolumn{4}{|l|}{ Ethnicity* } & \multirow[t]{4}{*}{0.002} \\
\hline western European & $672(77.1)$ & $174(77.3)$ & $498(76.2)$ & \\
\hline Surinamese or Antillean & $76(8.7)$ & $7(3.1)$ & $69(10.7)$ & \\
\hline other & $57(6.5)$ & $19(8.4)$ & $38(5.9)$ & \\
\hline \multicolumn{4}{|l|}{ Intravenous drug use } & \multirow[t]{3}{*}{$<0.0001$} \\
\hline ever injected & $710(81.4)$ & $217(96.4)$ & $493(76.2)$ & \\
\hline never injected & $162(18.6)$ & $8(3.6)$ & $154(23.8)$ & \\
\hline \multicolumn{4}{|l|}{ Duration of residence in Amsterdam ${ }^{\star}$} & \multirow[t]{4}{*}{0.02} \\
\hline$\leqslant 4$ years & $232(26.6)$ & $48(21.3)$ & $184(28.4)$ & \\
\hline $5-14$ years & $259(29.7)$ & $81(36.0)$ & $178(27.5)$ & \\
\hline$\geqslant 15$ years & $293(33.6)$ & $70(31.0)$ & $223(34.5)$ & \\
\hline \multicolumn{5}{|l|}{ Other characteristics } \\
\hline mean follow up period in years (SD) & $4.2(3.0)$ & $4.2(2.8)$ & $4.3(3.1)$ & $>0.05$ (NS) \\
\hline mean number of cohort visits (SD) & $10.9(7.4)$ & $11.6(7.2)$ & $10.7(7.4)$ & $>0.05$ (NS) \\
\hline
\end{tabular}

^Because of missings these variables do not add up to the total.

cohort to study the prevalence, incidence, and natural course of HIV infection. The study is carried out independently from any medical care facility and investigators are not involved in methadone distribution.

Participants are asked to return every four months to answer standardised questions, including medical history, treatment, and hospital admissions. At every cohort visit blood is drawn. Blood specimens are tested for HIV by two enzyme linked immunosorbent assays (ELISA; Abbott, North Chicago, Illinois, USA and Vironostica tecknika, Organon, Oss, the Netherlands) and positive specimens are confirmed by western blot test (Department of Human Retrovirology, Amsterdam Academic Medical Centre). To determine CD4 cell counts (systematically done since 1989), peripheral blood mononuclear cells are isolated from heparinised venous blood by using density gradient centrifugation on ficoll hypaque. Lymphocyte immunophenotyping is determined by flow cytometry (Department of Clinical Viro-immunology, Central Laboratory of the Bloodtransfusion Service).

To study the incidence of tuberculosis, 872 participants with at least one follow up visit, who were free of active tuberculosis at entry, were included. The diagnosis of active tuberculosis was only accepted if confirmed by a positive culture for $M$ tuberculosis. For the overall analysis follow up was censored after a first episode of tuberculosis, after the last cohort visit, or on 31 December 1995, the date of the final cross linkage with the tuberculosis register (see below). For CD4+ counts follow up was censored one year after the last cohort visit to limit measurement error. The average number of cohort visits was 11 (SD 7; range 2-33), the average duration of follow up was 4.2 year (see table 1).

When active tuberculosis was diagnosed, the patient register of the tuberculosis department of the Amsterdam Municipal Health Service was used to complete the cohort data. These included the mode of detection (classified as passive detection-that is, when a person sought help for symptoms and active casefinding - that is, when a person was called or sent for screening), clinical presentation, drug resistance (after 1991 determined routinely), results of IS6110-based restriction fragment length polymorphism (RFLP) analysis using standard methodology ${ }^{16}$ (systematically available since 1 January 1993, National Institute of Public Health and Environment) and treatment results.

The registration includes all tuberculosis patients residing in Amsterdam. Pulmonary localisation of tuberculosis was distinguished in "typical" and "atypical" radiological appearance. Typical radiological appearance was defined as focal infiltration in the upper segments of the upper or lower lobes, with or without cavitation. Pulmonary infiltrates in other sites, miliairy pattern, pleurisy, intrathoracal lymphadenitis or absence of abnormalities were considered atypical. ${ }^{17} 18$

Statistical comparison of general characteristics of the study population was done by $\chi^{2}$ and Student's $t$ tests. The cumulative incidences of tuberculosis among HIV negative and HIV positive participants were estimated with the Kaplan-Meijer survival method. HIV status was analysed as a time dependent variable: from entry to seroconversion seroconverters counted as HIV negative, from seroconversion to end point as HIV positive.

The relative hazard for tuberculosis among HIV positive participants as compared with HIV negatives was calculated with Cox proportional hazard analysis. We adjusted for the following potential confounders: sex, age, duration since first intravenous drug use, nationality, ethnicity, duration of residence in Amsterdam and year of entry in the study.

To study the relation between CD4+ cell numbers and tuberculosis incidence, poisson regression analysis was used. Because CD4+ cell numbers are routinely measured after 


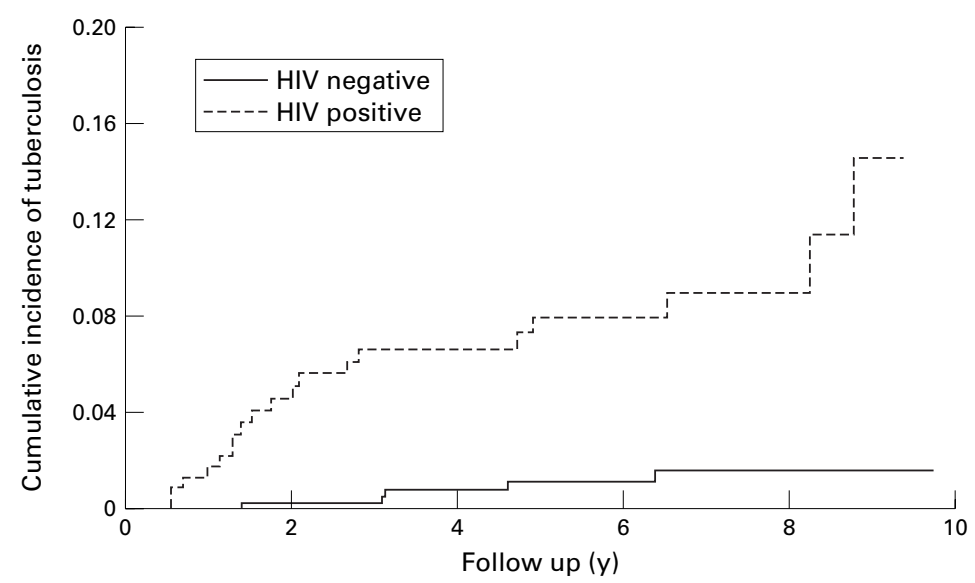

Figure 1 Cumulative incidences of active tuberculosis in HIV positive and HIV negative drug users, estimated with the Kaplan-Meier survival method.

Table 2 Cox's regression analysis: variables independently and significantly related to incidence of tuberculosis in a cohort of 872 Amsterdam drug users

\begin{tabular}{lll}
\hline Variable & Relative risk & $\begin{array}{l}95 \% \text { confidence } \\
\text { intervals }\end{array}$ \\
\hline $\begin{array}{l}\text { HIV infection* } \\
\text { Age at entry (y) }\end{array}$ & 12.85 & $3.38,48.81$ \\
$\quad \leqslant 27$ & 1.00 & \\
$28-32$ & 3.4 & $0.66,17.56$ \\
$\geqslant 33$ & 6.78 & $1.31,35.04$ \\
\hline
\end{tabular}

${ }^{\star}$ Time dependent variable.

1988, the calculated number of person years was reduced to 975 , with 14 tuberculosis cases. $\mathrm{p}$ Values lower than 0.05 were considered statististically significant (two sided). Analyses were performed with SPSS ${ }^{19}$ and EGRET. ${ }^{20}$

\section{Results}

At entry in the cohort study, 225 of a total of 872 participants $(26 \%)$ were HIV positive and 647 HIV negative $(74 \%)$. Apart from a strong relation between HIV infection and history of intravenous drug use, the HIV positive and HIV negative participants differed significantly with regard to nationality, ethnicity, and duration of residence in Amsterdam (table 1). During the study period 72 persons (11\%) seroconverted from HIV negative to HIV positive.

The total follow up period was 4000 person years (py): 1235 py for HIV positive people (including follow up of seroconverters after seroconversion) and 2765 py for HIV negative people (including follow up of seroconverters until time of seroconversion).

Table 3 Main characteristics of 24 tuberculosis patients

\begin{tabular}{|c|c|c|}
\hline Characteristics & $\begin{array}{l}\text { HIV positive } \\
(n=19)\end{array}$ & $\begin{array}{l}\text { HIV negative } \\
(n=5)\end{array}$ \\
\hline \multicolumn{3}{|l|}{ Mode of detection } \\
\hline passive case finding & 10 & 1 \\
\hline 6 monthly chest radiography & 9 & 4 \\
\hline \multicolumn{3}{|l|}{ Type of tuberculosis } \\
\hline only pulmonary (typical presentation ${ }^{\star}$ ) & $12(8)$ & $5(5)$ \\
\hline pulmonary+extra-pulmonary (typical presentation ${ }^{\star}$ ) & $5(1)$ & 0 \\
\hline extra-pulmonary & 2 & 0 \\
\hline Mean CD4 cell number per $\mu \mathrm{l}(\mathrm{SD}) \dagger$ & $390(220)$ & $800(180)$ \\
\hline TB diagnosis after 1 January $1993 \ddagger$ & 9 & 2 \\
\hline Occurrence in RFLP cluster & $5(55 \%)$ & $2(100 \%)$ \\
\hline
\end{tabular}

${ }^{\star}$ Focal infiltration with or without cavitation in apical segments of upper or lower lobes. $†$ Data from 14 HIV positive and 2 HIV negative patients. $\ddagger$ Date after which RFLP became systematically available.
Twenty four of 872 participants in the cohort study developed at least one episode of active tuberculosis, corresponding with an incidence of 0.60 per 100 py $(95 \%$ CI: $0.40,0.90)$. Nineteen cases occurred in HIV positive people: in 15 of the 225 participants who were already seropositive at entry and in four of the 72 participants who seroconverted, all four after seroconversion, resulting in a tuberculosis incidence among HIV positive people of 1.54 per 100 py (95\% CI: 0.86, 2.11). Of 575 participants who were HIV negative at entry five persons $(0.9 \%)$ developed active tuberculosis (incidence 0.18 per 100 py, $(95 \% \mathrm{CI}$ : $0.08,0.43)$. Figure 1 shows the Kaplan-Meier estimates of the cumulative incidences of active tuberculosis among HIV positive and negative participants.

In the univariate Cox model the relative hazard of tuberculosis in HIV positive drug users compared with HIV negative drug users was 8.5 (95\% CI: 3.2, 22.9). Age above 33 years, compared with age below 27 years, and male sex were univariate predictors for tuberculosis as well (RR: 5.5, 95\% CI:1.6, 19.4 and RR 3.7, $95 \% \mathrm{CI}: 1.3,10.7$ respectively). Other variables (see methods) did not show a significant association with tuberculosis incidence.

Multivariately, HIV infection increased tuberculosis risk nearly 13 times (table 2). Among the other variables only age was also independently related to tuberculosis: persons with age above 33 years carried a risk seven times higher than those with age below 27 years (table 2). There was no statistical interaction between HIV and the other variables.

Of the 19 HIV positive patients there were 14 CD4+ cell numbers available: these did not show a significant relation with tuberculosis incidence (RR for CD4+ strata 300-500/ $\mu$ and $<300 / \mu 1$ as compared with counts $>500 / \mu 1$ were 1.25, 95\% CI: $0.33,4.64$ and $1.05,95 \% \mathrm{CI}$ : $0.28,3.90$ respectively). The mean CD $4+$ cell number closest to tuberculosis diagnosis was 390/ $\mu 1$.

Seventeen of the 19 HIV positive participants developed tuberculosis before other AIDS defining conditions (according to the latest AIDS definition). The other two already suffered from AIDS before tuberculosis was diagnosed (for 2 and 10 months respectively).

Table 3 shows several characteristics of the 24 tuberculosis patients: 13 of 22 patients (59\%) with pulmonary localisation were detected through a screening programme consisting of half yearly radiological examination of the chest performed by the Municipal Health Service.

We saw typical radiological manifestations mostly in patients with only pulmonary tuberculosis. In 12 of 14 patients with typical presentation the smear of sputum or bronchial washing was Ziehl-Neelsen positive, compared with only two positive smears in eight patients with atypical presentation $(\mathrm{p}<0.05)$. In the seven patients with extra-pulmonary localisations $M$ tuberculosis was isolated from lymph gland (4 times); pleura (3 times); blood (2 times); bone marrow (once) and urine (once). From 11 patients $M$ tuberculosis was isolated 
after 1 January 1993, the date after which RFLP patterns became systematically available. Seven of these patterns (63\%) were part of four different clusters consisting of identical RFLP patterns (for the whole of Amsterdam). In one HIV positive patient a strain of $M$ tuberculosis resistant to isoniazid was isolated $(6 \%$ of 16 sensitivity tests). Tuberculosis relapsed in one HIV positive patient six years after the first episode. Finally, 23 of the 24 tuberculosis patients in the cohort completed the full nine month course of tuberculostatic drug treatment.

\section{Discussion}

Against a background of incidences of 0.03 and 0.006 culture confirmed cases of tuberculosis per 100 inhabitants per year in Amsterdam ${ }^{13}$ and the Netherlands ${ }^{21}{ }^{22}$ respectively, the incidence of 0.2 per 100 py in HIV negative drug users that was observed confirms that drug users in Amsterdam are at increased risk for tuberculosis irrespective of HIV serostatus. Whereas the incidence of 1.5 per 100 py among HIV infected drug users is extremely high for Dutch standards, it is relatively low compared with the $2.1-9.6$ per 100 py among drug users elsewhere in Europe and New York. ${ }^{93-27}$ This is probably explained by the smaller pool of drug users who are infected with $M$ tuberculosis in Amsterdam: $14 \%$ in $1986,{ }^{7}$ compared with $20-31 \%$ elsewhere. ${ }^{96}$ As tuberculosis is supposed to reactivate in roughly $8 \%$ annually in a HIV and tuberculosis infected population, ${ }^{925}$ we may estimate the incidence of tuberculosis attributable to reactivation in the HIV infected fraction of our cohort to be about $14 \%$ times $8 \%$-that is, $1 \%$ per year, which approximates to two thirds of the total incidence of tuberculosis we observed among HIV positive drug users. The association we observed between higher age and active tuberculosis further confirmes the major role of reactivation in the incidence of tuberculosis. On the other hand progressive primary tuberculosis resulting from recent transmission did occur as is illustrated by the identical RFLP patterns. In a recent study a high degree of active transmission of $M$ tuberculosis was found for Amsterdam as a whole, and especially for hard drug users. ${ }^{13}$

As tuberculosis infection in drug users is expected to occur independently of HIV infection, the immunodeficiency induced by HIV is likely to be responsible for the 13-fold increased risk for active tuberculosis in our cohort. A comparable risk was found in New York and Sao Paulo, ${ }^{28}{ }^{29}$ whereas a higher relative hazard was observed among young women in Ruanda and Zaïre. ${ }^{23}$

In our cohort, tuberculosis was nearly always diagnosed before other AIDS defining conditions. The relatively high $\mathrm{CD} 4+$ counts at tuberculosis diagnosis and typical radiological appearance of most pulmonary lesions further complies with a diagnosis early in the course of HIV infection. ${ }^{18}$ The relation observed between typical radiographic manifestations and positive sputum smears corresponds with the
KEY POINTS

- HIV infection increases the risk for active tuberculosis in Amsterdam drug users 13-fold.

- The incidence of tuberculosis in HIV negative drug users is still six times higher than in the overall Amsterdam population.

- In the absence of contact tracing and screening with tuberculin skin tests, periodic chest radiographic screening contributes substantially to early case finding of active tuberculosis.

- Tuberculosis is detected early in the course of HIV infection.

- The harm reduction approach offers a framework for the control of tuberculosis.

finding that pulmonary lesions may be more infectious in the relatively immunocompetent host. ${ }^{30}$

Theoretically thorough contact investigations or a massive programme consisting of tuberculin skin testing followed by isoniazid prophylaxis should profoundly reduce the incidence of reactivation tuberculosis and consequently interrupt the chain of transmission. However, in our experience most drug users provide insufficient information on contacts, do not return for skin test reading and are hard to motivate for preventive treatment. Given the absence of this preventive intervention, active case finding by chest radiographic screening, at a detection rate of $60 \%$ of all pulmonary cases in the cohort, seems to be an effective alternative in this population. Even before symptoms arise, a small infiltration visible on the chest radiograph, usually has strong positive influence on the motivation for treatment. The added support of public health nurses supervising the adequate intake of medications, including adjusted methadone doses to compensate the increased breakdown by rifampicin, provided in our patients an excellent treatment outcome. Drug resistance occurred rarely, which contrasts with a study from New York, where multiple drug resistance was frequent and associated with HIV infection. ${ }^{31}$

The representativeness of the study population is unknown, as there is no registration of those who refused participation given referral of interested participants mainly via methadone programmes. Furthermore, visitors who returned for follow up visits, compared with single visitors, were more often of Dutch nationality, male gender, HIV positive or currently injecting. As a result, the estimates of the incidence of tuberculosis may be biased. However, it is unlikely that the relation between HIV infection and tuberculosis is overestimated. Also, our findings were corroborated by previous observations - that is, an overall tuberculosis incidence of 0.60 per 100 py among 3000 clients of the Municipal Health Service's methadone clinics, ${ }^{11}$ and an annual tuberculosis incidence of 1.8 per $100 \mathrm{HIV}$ positive drug users, based on an annual average of 14 notified cases of TB in HIV infected drug 
users $^{14}$ and the estimated population of 800 HIV infected drug users in Amsterdam. ${ }^{32}$

We conclude that HIV infection strongly increases the risk for tuberculosis among Amsterdam drug users. Tuberculosis is detected early in the course of HIV infection. HIV negative drug users develop tuberculosis much more often than the average inhabitant of Amsterdam. The harm reduction approach offers a framework for the control of tuberculosis in Amsterdam drug users.

The Amsterdam cohort studies HIV/AIDS represent a collaborative effort between the Department of Public Health and Environment of the Municipal Health Service of Amsterdam, the Departments of Retrovirology and Internal Medicine of the Academic Medical Center, University of Amsterdam and the Department of Clinical Viro-Immunology of the Central Laboratory of the Red Cross Bloodtransfusion Service and Laboratory for Experimental and Clinical Immunology, University of Amsterdam.

Funding: the study was supported by the Netherlands Foundation for Preventive Medicine.

Conflicts of interest: none.

1 Tuberculosis-United States, 1985-and the possible impact of human T-lymphotropic virus type III/lymphadenopathyassociated virus infection. MMWR 1986;35:74-6.

2 Allen S, Batungwanayo J, Kerlikowske K, et al. Two year incidence of tuberculosis in cohorts of HIV-infected and uninfected urban Rwandan women. Am Rev Respir Dis 1992;146:1439-44.

3 Braun MM, Nsanga B, Ryder RW, et al. A retrospective cohort study of the risk of tuberculosis among women of childbearing age with HIV infection in Zaire. Am Rev Respir Dis 1991;143;501-4.

4 Keizer ST, Broekmans JF, Bilkert-Mooiman MAJ. Tuberculosis onder buitenlanders: Vóórkomen en opsporingswijze, losis onder buitenlanders: Vóórkom

5 Reichman LB, Felton CP, Edsall JR. Drug dependence, a possible new risk factor for tuberculosis disease. Arch Intern Med 1979;139:337-9.

6 van den Hoek, JAR, Coutinho RA, van Haastrecht HJA, et al. Prevalence and risk factors of HIV infections among drug users and drug using prostitutes in Amsterdam. AIDS 1988;2:55-60.

7 Hartgers C, van den Hoek, JAR, Krijnen P, et al. HIV prevalence and risk behaviour among injecting drug users who participate in 'low threshold' methadone programs in Amsterdam. Am F Public Health 1992;82:547-51

8 Fennema JSA, van Ameijden EJC, van de Hoek JAR, et al. De HIV-prevalentie bij intraveneuze druggebruikers in Amsterdam: een onderzoek op straat. T Soc Gezondheidsz 1993;71:267-72.

9 Selwyn PA, Hartel D, Lewis VA, et al. A prospective study of the risk of tuberculosis among intravenous drug users with the risk of tuberculosis among intravenous drug users with human immunode

10 Manos GE, van Santen GW, Leentvaar-Kuijpers A, et al. Tuberculin and "multitest" skin-tests in drug abusers. Lancet 1987 ;ii:567-8.

11 van Brussel GHA, Buster MCA, Nasseri K, et al. Incidence of tuberculosis among drug addicts in Amsterdam methadone programmes. Eur F Public Health 1995;5:253-8.
12 Anon. Beleid ten aanzien van risicogroepen voor tuberculose in Nederland, rapportage van de Commissie voor Practische Tuberculosebestrijding. (Report on casefinding among groups at risk, Tuberculosis Policy Committee). The Hague: Royal Netherlands Tuberculosis Association (KNCV), 1995:15.

13 van Deutekom H, Gerritsen JJJ, van Soolingen D, et al. A molecular epidemiological approach to studying the transmission of tuberculosis in Amsterdam. Clin Infect Dis 1997; 25:1071-7.

14 Anon. Faarverslagen Tuberculose bestrijding, 1990-1995. Amsterdam: Amsterdam Municipal Health Service, Division of Public Health and Environment, Tuberculosis Department, 1996.

15 van Deutekom H, Mientjes GHC. Tuberculose bij druggebruikers in Amsterdam. Ned Tijdschr Geneeskd 1991;135: 1060 .

16 van Embden JDA, Cave MD, Crawford JT, et al. Strain identification of $M$ tuberculosis by DNA fingerprinting: recommendations for a standardized methodology. 7 Clin Microbiol 1993;31:406-9.

17 Barnes PF, Bloch AB, Davidson PT, et al. Tuberculosis in patients with human immunodeficiency virus infection. $N$ Engl f Med 1991;324:1644-9.

18 Post FA, Wood R, Pillay GP. Pulmonary tuberculosis in HIV infection: radiographic appearance is related to $\mathrm{CD} 4+\mathrm{T}$ lymphocyte count. Tuber Lung Dis 1995;76:518-22

19 Norusis MJ, SSPC/PC+ 4.0 Base manual. Chicago: Statististical Package for Social Sciences Inc, 1990.

20 Statistics and Epidemiology Research Corporation. Epidemiological graphics estimation and testing package, draft manual. (3rd ed). Seattle, USA: 1992.

1 Anon. Index tuberculosis. The Hague: Royal Netherlands Tuberculosis Association KNCV, 1994:41,71.

22 Anon. Index tuberculosis. The Hague: Royal Netherlands Tuberculosis Association (KNCV), 1995:39,65.

23 Antonucci G, Girardi E, Raviglione M, et al. Risk factors for tuberculosis in HIV-infected persons, a prospective cohort study. ҰAMA 1995;274:143-8.

24 Dupon M, Texier-Maugen J, Jeroy V, et al. Tuberculosis and HIV infection: a cohort study of incidence and susceptibility to antituberculous drugs, Bordeaux, 1985-1993. AIDS 1995;9:577-83.

25 Guelar A, Gatell JM, Verdejo J, et al. A prospective study of the risk of tuberculosis among HIV-infected patients. AIDS 1993; 7:1345-9.

26 Moreno S,Baraia-Etxaburu J, Bouza E, et al. Risk for developing tuberculosis among anergic patients infected with HIV. Ann Intern Med 1993;119:194-8.

27 Jansà JM, Serrano J, Caylà JA, et al. Influence of the human immunodeficiency virus in the incidence of tuberculosis in a cohort of intravenous drug users: effectiveness of anti-tuberculosis chemoprophylaxix. Int $\mathcal{f}$ Tuberc Lung Dis 1998;2:140-6.

28 Selwyn PA, Sckell BM, Alcabes P, et al. High risk of active uberculosis in HIV-infected drug users with cutaneous anergy. FAMA 1992;268: 504-9.

29 Ferreira MMC, Ferrazoli L, Palaci M, et al. Tuberculosis and HIV infection among female inmates in São Paulo, Brazil: A prospective Cohort study. F Acquir Immune Defic Syndr Hum Retrovirol 1996;13:177-83.

30 Cauthen GM, Dooley SW, Onorato IM, et al. Transmission of Mycobacterium Tuberculosis from tuberculosis patients with HIV infection or AIDS. Am f Epidemiol 1996;144:69-

31 Gordin FM, Nelson,ET, Matts, JP, et al. The impact of human immunodeficiency virus infection on drug-resistant tuberculosis. Am 7 Respir Crit Care Med 1996; 154:147883.

32 van Ameijden EJC. Evaluation of Aids-prevention measures among drug users: The Amsterdam Experience. [Thesis]. Amsterdam: University of Amsterdam, 1994:16. 